\title{
An overview of the slope monitoring program at the Serra Sul Iron Ore Project, S11D, northern Brazil
}

\author{
MF Souza Vale S.A., Brazil \\ E Friguetto Vale S.A., Brazil \\ WJ Souza Vale S.A., Brazil \\ AHCR Castro Vale S.A., Brazil
}

\begin{abstract}
The Serra Sul Iron Ore Project, located in state of Pará, northern Brazil, is one of the largest mining complexes in Vale S.A.'s, history with state-of-the-art mining technology. Operations began in 2017, which saw the application of conveyor systems as the replacement for traditional haul trucks for open pit mining. Ore and waste are transported from mining faces, to the processing plant and waste dumps respectively by conveyor belts. As the mine is ramping up production and the mining area is still on a plateau, slope monitoring at Serra Sul is focussed especially on slopes and soil embankments built to carry a road for conveyor infrastructure. The project has approximately $37 \mathrm{~km}$ of conveyors that are assembled on top of cut-and-fill slopes. They are monitored through satellite-based interferometric synthetic aperture radar (InSAR), prism monitoring and visual inspections-on foot and using an unmanned aerial vehicle (drone). An overview of the geotechnical monitoring program and methods used at Serra Sul, the locations of the currently monitored areas, and an analysis of the dataset collected will be presented in this paper.
\end{abstract}

Keywords: slope monitoring, visual inspection, prism monitoring, satellite-based InSAR

\section{Introduction}

The Serra Sul Iron Ore Project (Serra Sul) is located in the north of Brazil, in the state of Pará (Figure 1). Mining was initiated in 2017 at the S11 orebody, block D. According to Vale S.A. $(2013,2019)$, the mineral potential of the S11 orebody is 10 billion metric tonnes of iron ore, and block $D$ alone has proven and probable reserves of 4.28 billion metric tonnes.

The iron ore consists of hematite, with approximately $65 \%$ iron content. As the ore deposit is mainly platy and friable, it was possible to adopt a unique mining method-a truckless in-pit crushing system that can achieve significantly high production rates. In 2020, it is estimated that Serra Sul will supply 90 million metric tonnes of iron ore.

There are currently four mining faces in Serra Sul. The active mining faces are called systems, as each of them has its own excavator connected to a mobile crusher, a bridge conveyor and a bench conveyor belt (Figure 2).

The waste material is mainly jaspelite and canga, which is mined and transported the same way as the hematite. Both waste and ore are taken from the conveyor belt to other connecting belts and then to the transfer house. At the transfer house, waste goes to the waste dump and ore goes to the processing plant.

This paper presents an overview of the geotechnical monitoring program and methods used at Serra Sul, the locations of the currently monitored areas, and a case study over transfer house 07. 


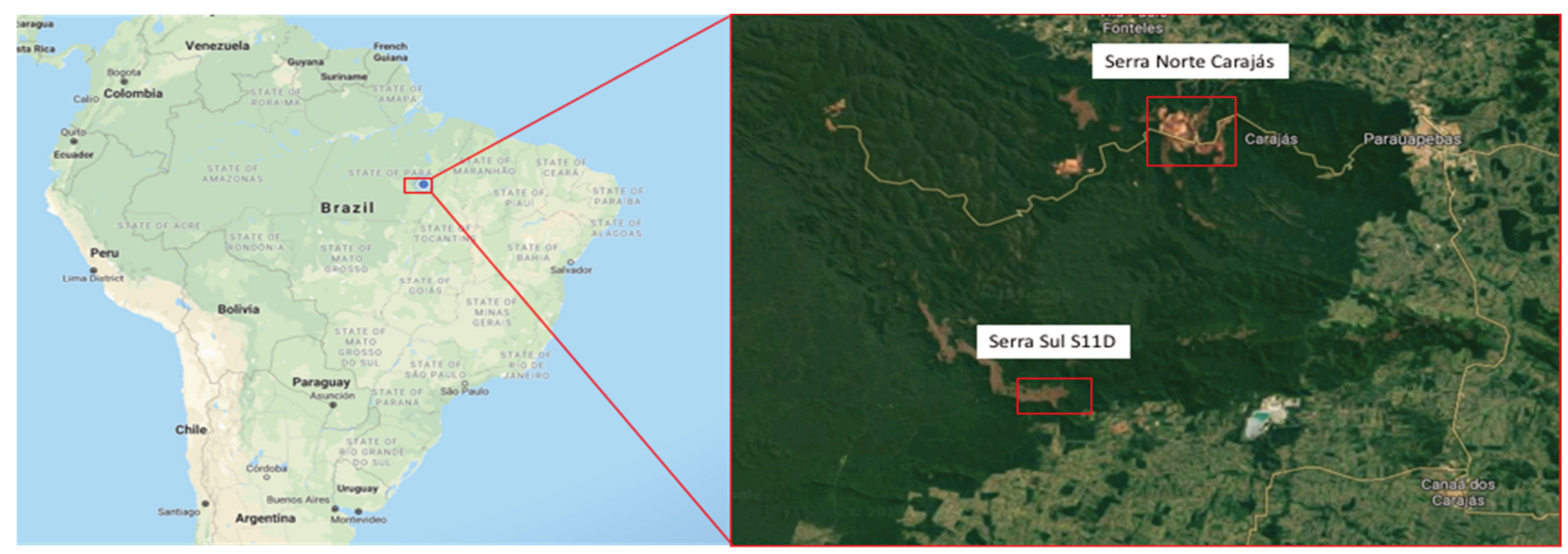

Figure 1 Geographic location of the Serra Sul Iron Ore Project, S11D

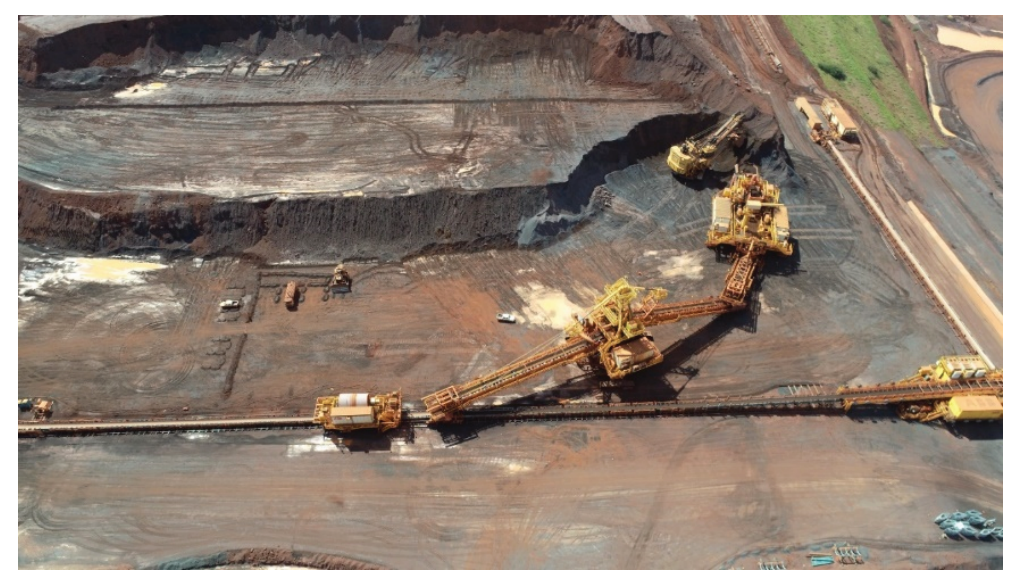

Figure 2 Standard system setup: excavator, mobile crusher, bridge conveyor and bench conveyor belt

\section{$2 \quad$ Monitoring systems at Serra Sul}

Geotechnical infrastructure should be measured and evaluated continuously for safety purposes in the form of a monitoring programme, designed and implemented to record deformation of both man-made and natural slopes. These slope structures comprise open pits, waste dumps, tailings dams, conveyor belts embankments, ore, waste piles, etc. At Serra Sul, as the mine is ramping up production and the mining area is still on a plateau, geotechnical monitoring is focussed especially on slopes and soil embankments built to carry a road for conveyor infrastructure. Serra Sul has approximately $37 \mathrm{~km}$ of conveyor belts that are assembled on top of cut-and-fill slopes. These slopes are monitored through satellite-based interferometric synthetic aperture radar (InSAR), prism monitoring and visual inspections.

The three methods are complementary. InSAR has a broader coverage of the Serra Sul Complex, while prism monitoring is focussed on specific locations of geotechnical interest, and visual inspections are scheduled and conducted at multiple pre-defined areas of the complex. Figure 3 shows the locations of the principal sectors of Serra Sul-the open pit mine, the waste dump and the processing plant-together with the indicated areas that are covered by InSAR and prism monitoring. 


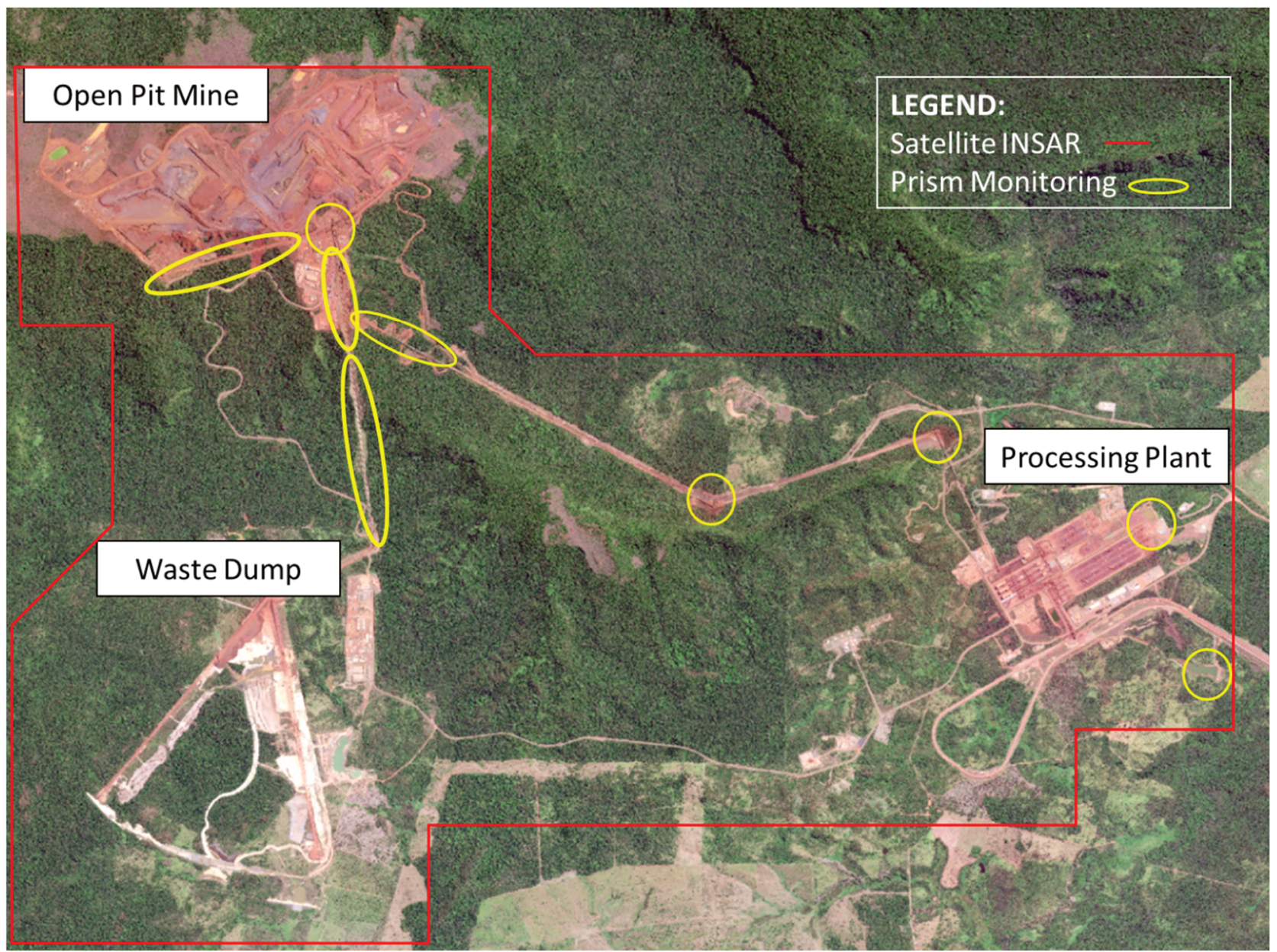

Figure 3 Locations of the principal sectors of Serra Sul: the open pit mine, the waste dump and the processing plant, together with the indicated areas that are covered by InSAR and prism monitoring. Highlighted in red is the satellite monitoring coverage boundary and in yellow circles is the survey monitoring area

\section{$2.1 \quad$ InSAR data}

Satellite synthetic aperture radar technology is a tool for the detection of slow ground deformation of large areas, such as Serra Sul. Movement in the scale of millimetres to centimeters can be quantified assertively by this method. Indication of movement caused by subsidence and earthflows (mine-induced instability or natural degradation) are some common applications of this monitoring technique. The basic principle of InSAR is the determination of the interferometric phase-that is the phase difference between two synthetic aperture radar (SAR) images acquired in different moments (time periods) and through distinct a line of sight. The phase difference is correlated to the site topography and to the deformation contained in the time frame between the two image acquisitions.

The Serra Sul site has been fully monitored using InSAR techniques since 2017, encompassing approximately $67 \mathrm{~km}^{2}$ of the project area. Processed imaging from X-Band COSMO-SkyMed satellites is delivered every two months and then provided to the geotechnical team as four deformation map datasets: ascending orbit, descending orbit, vertical and east-west (E-W).

The outcome is four deformation maps, displaying the persistent scatters (PS) monitored points that return stable signals to the satellite sensor, these being mean velocity, approximately equivalent to a 12 month cumulative displacement measurement. 
Imaging resolution is $3 \mathrm{~m}^{2}$ with StripMap Himage, and PS displacement accuracy is typically 3 to $5 \mathrm{~mm}$ (standard deviation). The PS mean velocity maps are products of processing 48 SAR images (double geometry, 48 ascending line of sight (LOS) and 48 descending LOS).

According to Constantini et al. (2016), vertical and E-W PS information are available if both ascending and descending geometries are available, as the ascending and descending SAR acquisition LOSs lie on a plane practically perpendicular to the north-south direction. Due to this, the SAR satellite is almost insensitive to movements in the $\mathrm{N}-\mathrm{S}$ direction, while it is sensitive to $\mathrm{E}-\mathrm{W}$ and vertical movements. The calculation of the $\mathrm{E}-\mathrm{W}$ and vertical components of movement are obtained by simple geometrical relations of the ascending and descending vectors. Figure 4 shows the four maps, indicating the mean PS velocities, approximately relative to one year.

Measurements for the ascending LOS (I), descending LOS (II), positive values indicate movement towards the satellite LOS. For the E-W measurement (III), positive values indicate movement towards the east direction. For the vertical measurement (IV), positive values indicate uplift movement.
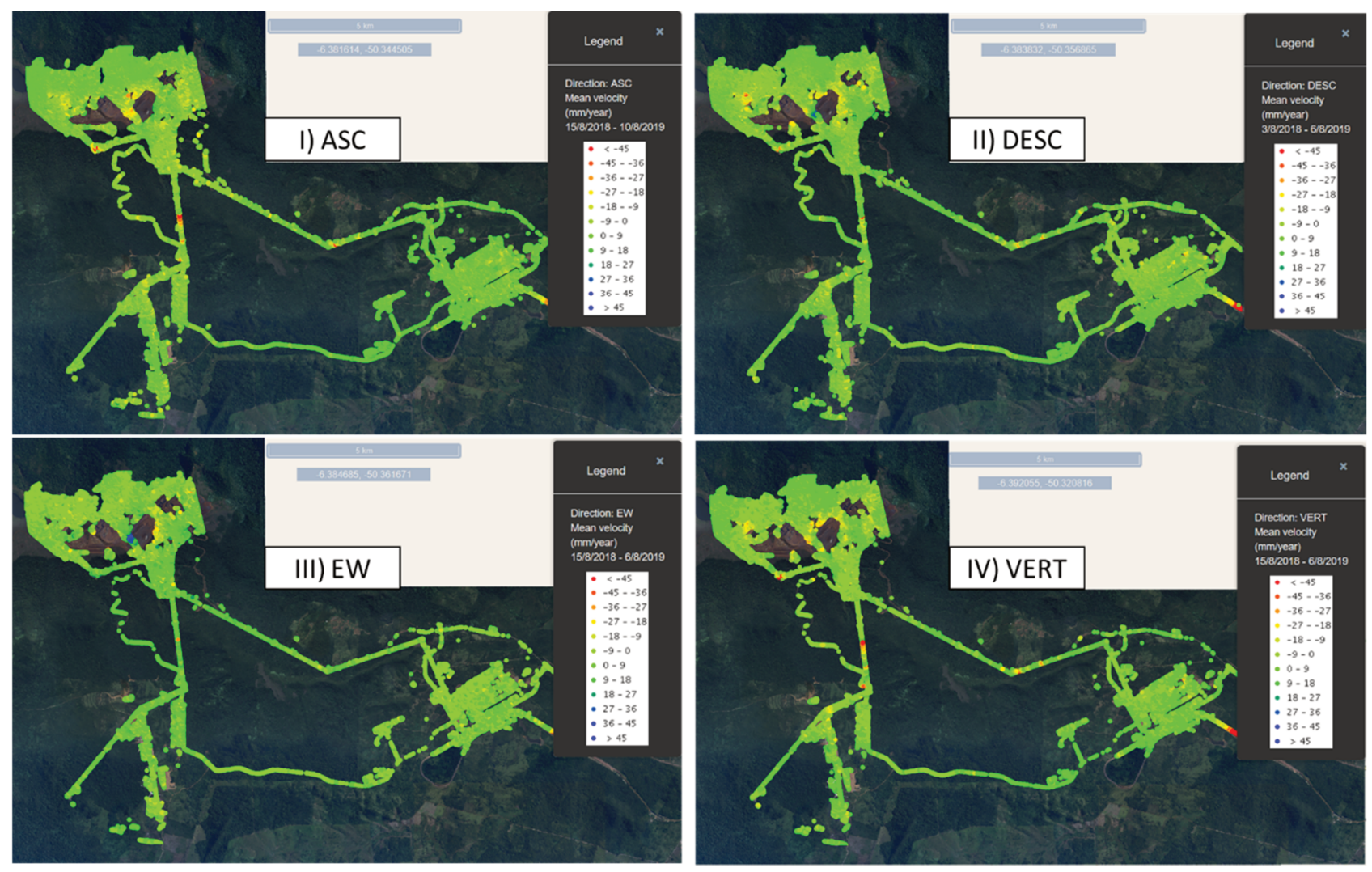

Figure 4 Velocity maps, ascending and descending orbit, vertical and E-W. The maps indicate PS mean velocities relative to one year (15 August 2018 to 10 August 2019)

When movement is detected by satellite-based InSAR, prism monitoring and a visual inspection routine are implemented for higher level of monitoring control.

\subsection{Prism monitoring}

Prism monitoring is executed using a robotic total station (RTS) at multiple locations in the Serra Sul complex. S9 Trimble RTS is used for data gathering and Trimble 4D Control monitoring software for data processing. S9 RTS has a $0.5^{\prime \prime}$ to $1^{\prime \prime}$ angular accuracy and a $1.0 \mathrm{~mm}+2 \mathrm{ppm}$ distance accuracy, relative to the distance between the target and the total station. Currently, there are nine major areas that are monitored once or twice a week through the monitoring campaign method. These areas can be subdivided into multiple field projects to have a wider coverage of the monitored target using more than one LOS. The data is collected in the field and downloaded at the geotechnical office from the total station controller to the processing 
software. Displacements in the $\mathrm{E}-\mathrm{W}, \mathrm{N}-\mathrm{S}$ and vertical direction, in the $2 \mathrm{D}$ and $3 \mathrm{D}$ realm are assessed to determine rates and direction of movement.

Figure 5 shows some of the cut-and-fill slopes along the conveyor belts that are monitored by field instrumentation at Serra Sul.
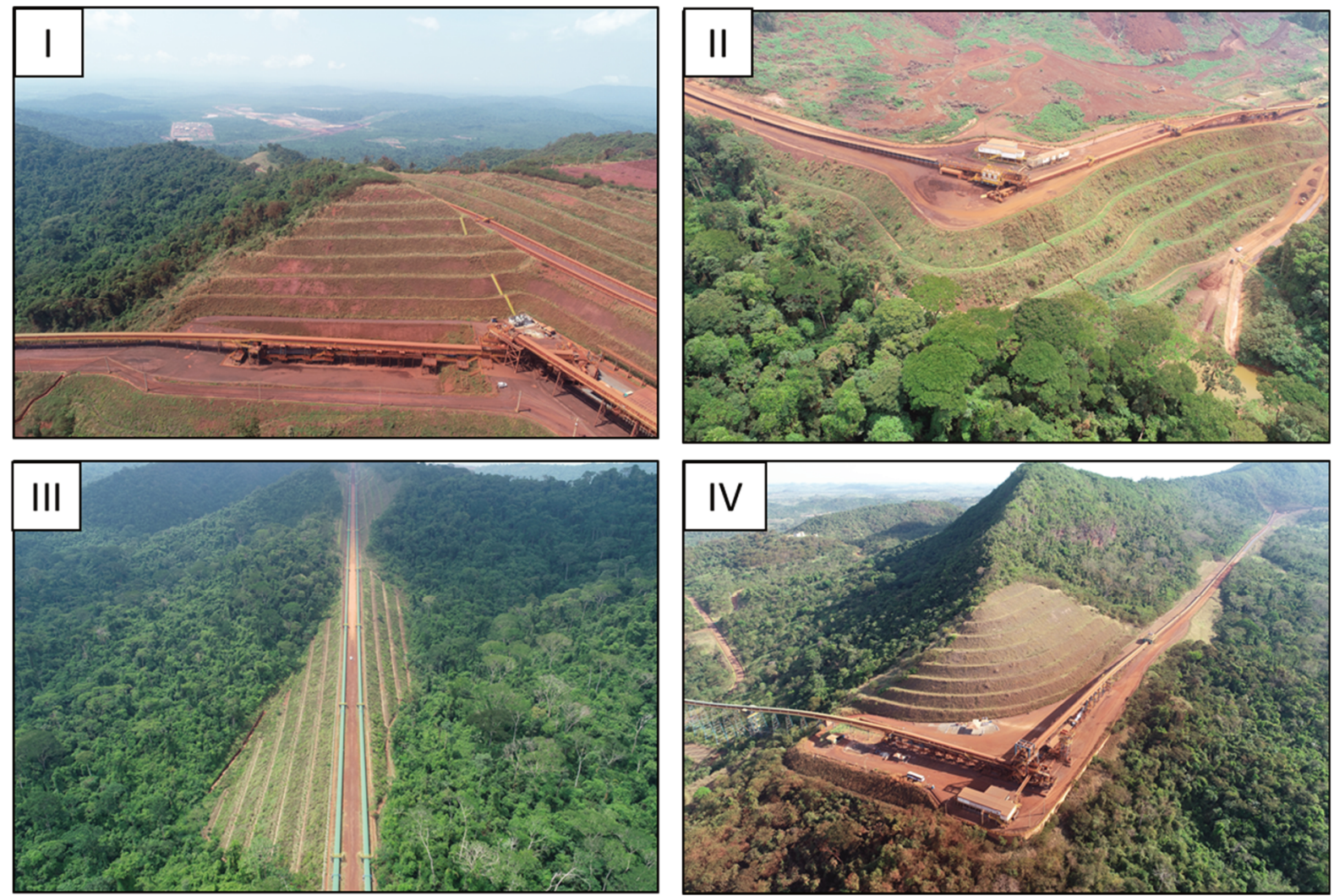

Figure 5 Aerial view of four cut-and-fill slopes that are monitored by field instrumentation at Serra Sul. From I to IV: CT-2, Corredor Oeste, Overland and CT-7

The challenges of slope stability monitoring using prisms at Serra Sul are the loss of measurement due to dusty conditions or by the growth of vegetation. Therefore, it is significantly important to keep the slopes groomed, perform regular housekeeping of the prisms and avoid acquisition of data when the weather conditions are inadequate. The routine in the field includes gently cleaning the prism surface with a dry rag to maintain the mirror visibility through the glass of the prism. Water is never applied during this process as it can worsen the visibility by adding more dust to the prism's surface.

\subsection{Visual inspections}

Visual inspections at the mining perimeter and around the conveyors are performed routinely by the operational and geotechnical staff. Special inspections are mandatory when a significant anomaly is highlighted to the geotechnical team, and consultant inspections are requested when necessary. Most of the inspections are executed on foot, where access is possible. Locations considered unsafe for access by mine personnel are monitored using an unmanned aerial vehicle (drone). Visual inspections at Serra Sul include checking for tension cracks, subsidence, small earthflows and rockfalls.

Another important check when performing an inspection is to analyse the integrity of the water drainage canals. Due to the location of the site and the tropical Amazon climate, annual precipitation can average up to $2,500 \mathrm{~mm}$. If the drainage system is interrupted or broken, the chances of having unstable conditions rises significantly. Anomalies observed during visual inspections are mapped, photographed, and recorded for further evaluation and mitigation. 


\section{Data assessment and analysis - transfer house 07}

A detailed investigation of one of the monitored areas is presented in this paper. Transfer house 07, also known as CT-7, is near one of the highest slopes situated along conveyor belts at the site (Figure $5 \mathrm{IV}$ ). The geotechnical team monitors both the behaviour of the slope and the embankment where the conveyor belts are located. The InSAR data produces the velocity maps of the CT-7, relative to the acquisition period of 15 August 2018 to 10 August 2019 (Figure 6).

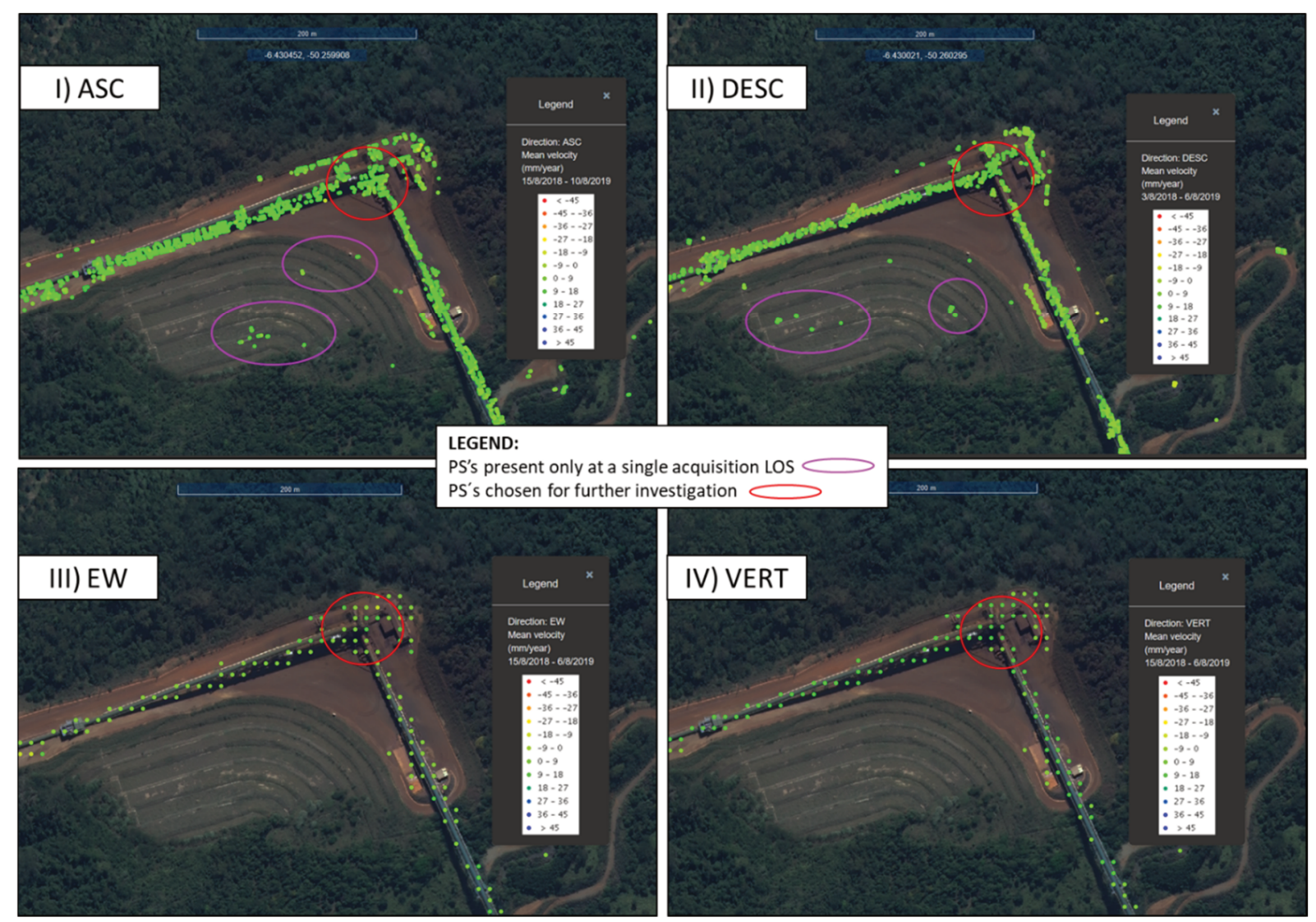

Figure 6 Velocity maps illustrating both I) ascending and II) descending orbit, III) E-W and IV) vertical of the CT-7 area (15 August 2018 to 10 August 2019)

Some persistent scatter points are present only at a single acquisition LOS (refer to the purple circles at Figure 6). It is noticeable that the higher density of PSs are displayed at the ascending and descending maps compared to the vertical and $\mathrm{E}-\mathrm{W}$ maps. As mentioned in Section 2.1, the calculation of the $\mathrm{E}-\mathrm{W}$ and vertical components of movement are obtained by simple geometrical relations of the ascending and descending vectors. If a PS is present at only one acquisition LOS, it would not be possible to calculate vertical and E-W vectors. That said, it is paramount to evaluate the four velocity maps, as well as the temporal displacement evolution of the PSs, to have a full understanding of the deformation.

It can be observed that most PSs are placed on top of infrastructure rather than at the slope itself. This comes down to the limitation of this method, which is due to temporal and geometrical decorrelation, and atmospheric inhomogeneities. This is discussed by Ferretti et al. (2001):

\footnotetext{
"Temporal decorrelation makes InSAR measurements unfeasible over vegetated areas and where the electromagnetic profiles and/or positions of the scatters change with time within the resolution cell. Geometrical decorrelation limits the number of image pairs suitable for interferometric applications and prevents one from fully exploiting the dataset available. Atmospheric inhomogeneities create an atmospheric phase screen superimposed on each SAR image that can seriously compromise accurate deformation monitoring."
} 
The CT-7 area has not shown significant movement over the past three years through satellite-based InSAR. The cumulative displacement time series of the previously circled PSs in red are shown in Figure 7. The four cumulative displacement plots indicate relative stability of the area. Most of the displacement measurements vary in the -5 to $+5 \mathrm{~mm}$ range, which is within the accuracy of the method (Constantini et al. 2011).

See Figure 7 for measurements for the ascending LOS (I) and descending LOS (II); positive values indicate movement towards the satellite LOS. For the E-W measurement (III), positive values indicate movement towards the east direction. For the vertical measurement (IV), positive values indicate uplift movement.

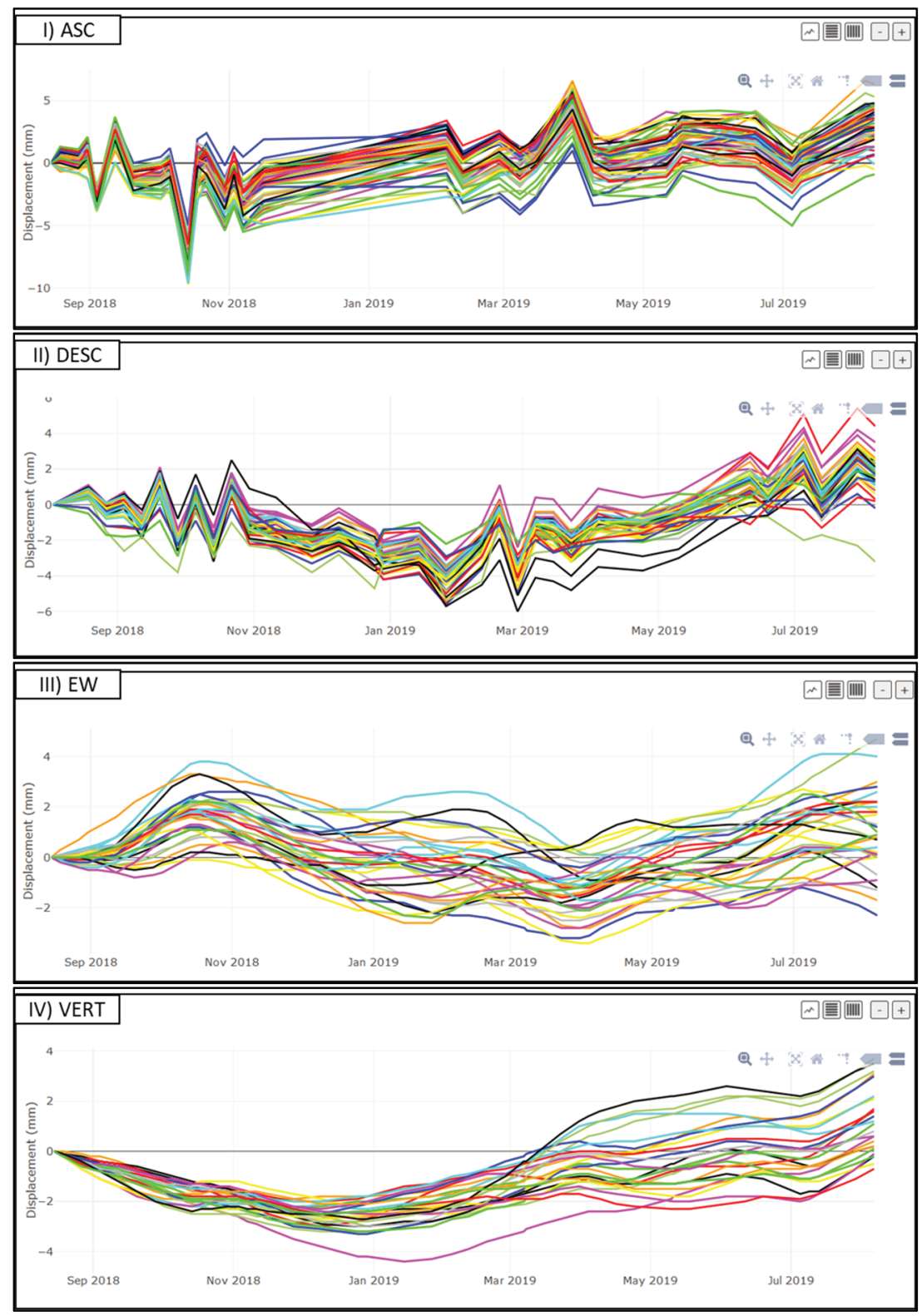

Figure 7 Cumulative PSs displacement plots: I) ascending and II) descending orbit, III) E-W and IV) vertical of the CT-7 area (15 August 2018 to 10 August 2019). The data displayed is relative to the circled areas in red in Figure 6

At this location, there are currently four prism monitoring field projects, aiming to cover the full extent of the target: an excavated slope and a soil embankment below the conveyor belts. The location of each instrument is shown in Figure 8. Each prism project is indicated as an assigned colour. CT-7 A and B cover the slopes parallel to the conveyor belts, while CT-7 C and D cover the fill embankment on the lower level. 


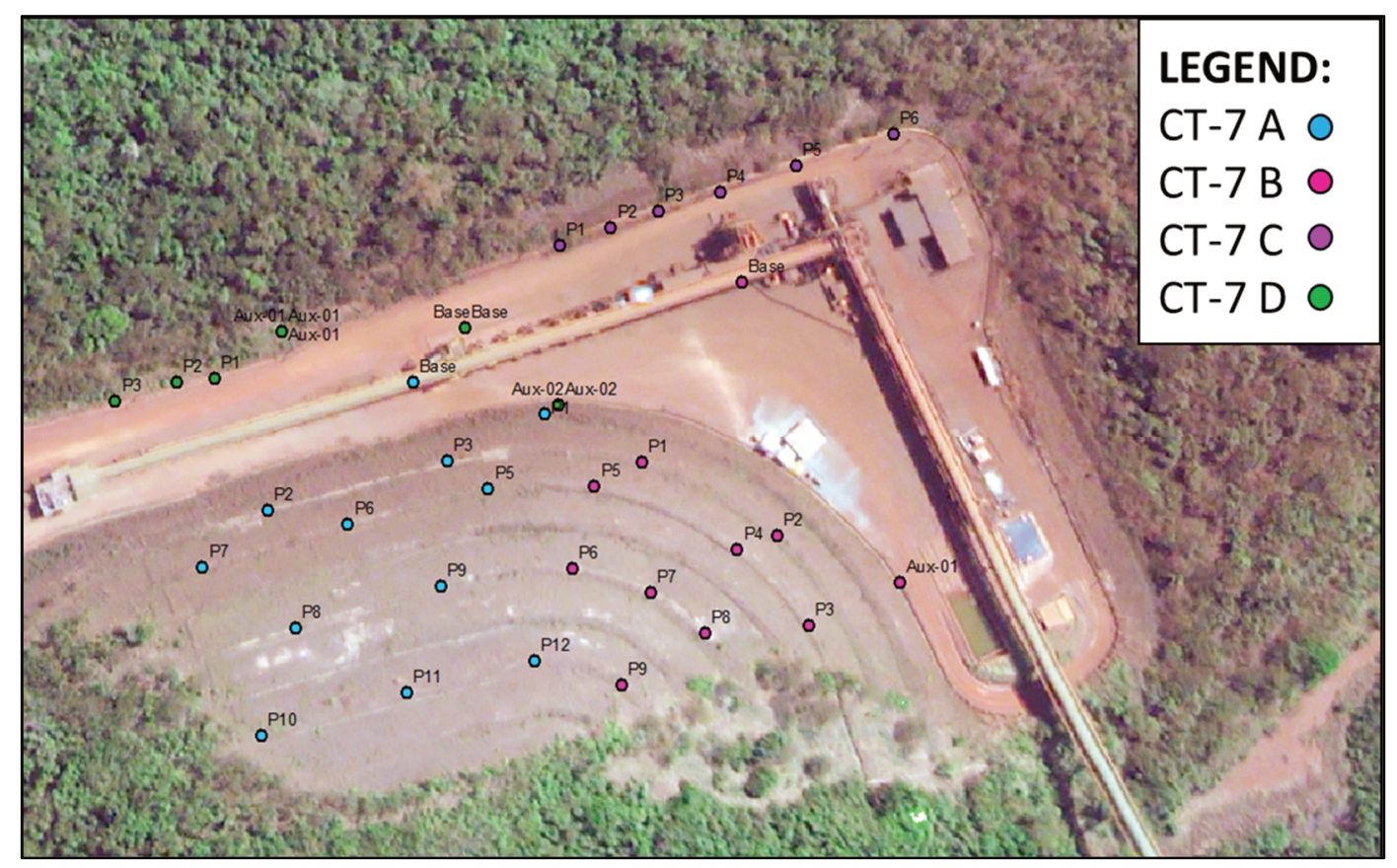

Figure 8 Top view of transfer house CT-7 and the slopes near the conveyor belts. There are four prism monitoring field projects. Each prism project is indicated as the assigned colour. Prisms are called P1, P2, P3, etc., and reference beacons are Aux-01, Aux-02, etc.

The prism monitoring data is shown in Figure 9. Each plot presents the tri-dimensional displacement of the prism targets of each field project. Positive and negative values are relative to the direction of the displacement vector. Prism data is presented for the last 450 days, starting in August 2018, analogous to the InSAR starting acquisition time. Notice that the prism data time frame is $25 \%$ longer compared to the InSAR data, as the satellite images have to be processed and data is never up to date.

The slope behaviour is relatively stable, as observed at the CT-7 A and B graphs. However, CT-7 C and D illustrate a number of targets that had significant displacements. In this case, a visual inspection was necessary to investigate the causes of movement and evaluate the risk profile in terms of likelihood and consequence for personnel and/or equipment.

In the case of prism P5 of CT-7 C, it was concluded that the movement might have happened due to equipment interference; a road grader could have pushed the instrument while levelling the ground surface. There were no other signs of natural movement at this prism point.

Prisms P1, P2 and P3 of CT-7 D are located parallel to the crest of the embankment. After the indication of movement through survey monitoring, the geotechnical team identified tension cracking parallel to the embankment crest (Figure 10). The anomaly initiated during the rainy season (April 2018). It is believed that cracking developed by the lack of compaction of the embankment near the edge (as for safety reasons, compaction equipment might not approach the edges of embankments). It was recommended to seal the crack to avoid surface water percolation and further development of movement by saturation and erosion. Movement has stabilised since the end of the rainy season. Unfortunately, due to temporal decorrelation, InSAR data was not available at the area where cracking developed, which made it impossible to compare survey monitoring to the interferometric method. 

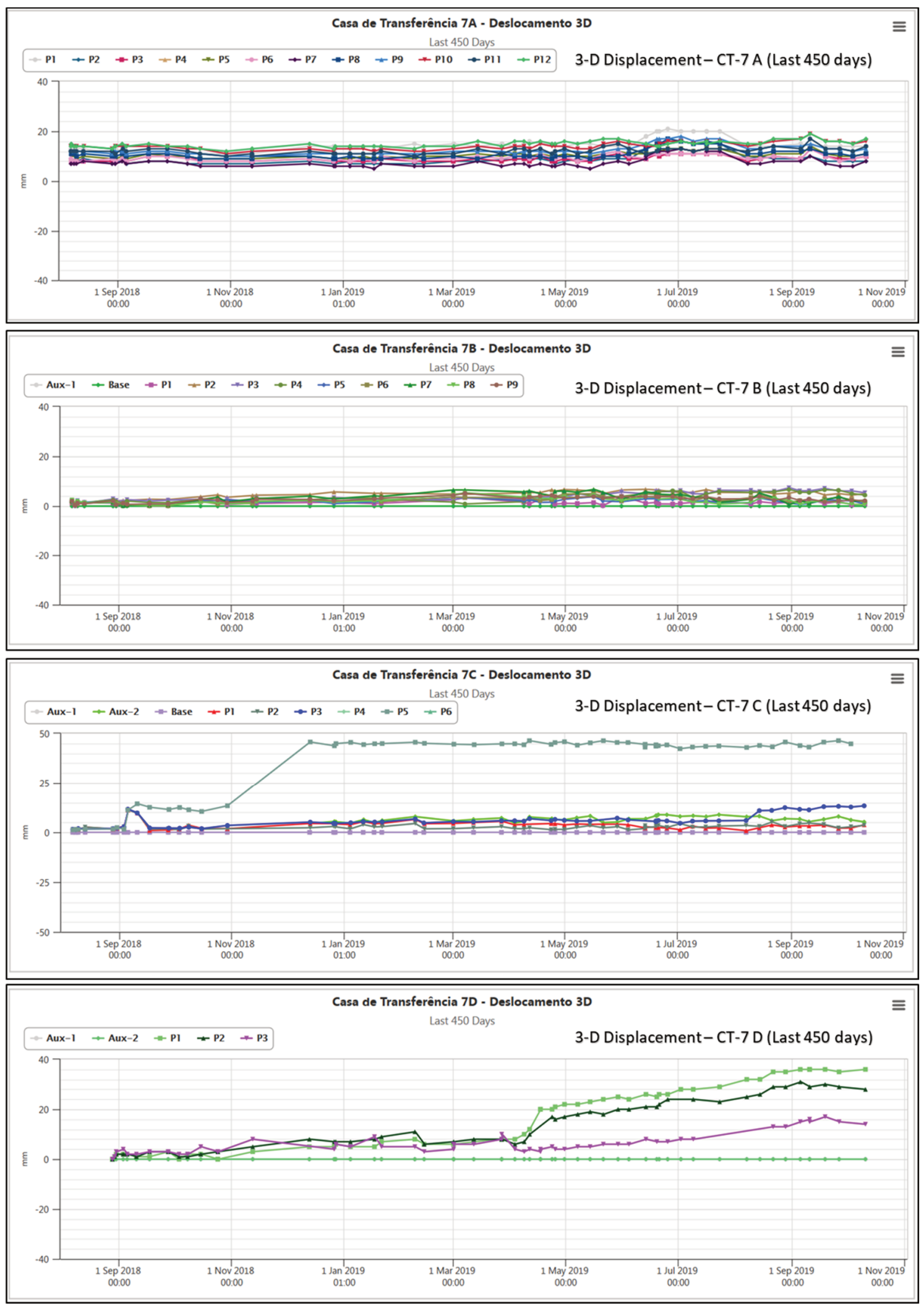

Figure 9 The plots indicate the tri-dimensional cumulative displacement of the prism targets, respective to each surveying project for the last 450 days, starting in August 2018. Positive and negative values are relative to the direction of the displacement vector. The slope behaviour is relatively stable, as observed at the CT-7 A and B plots. However, CT-7 C and D pointed out targets that had significant displacements 


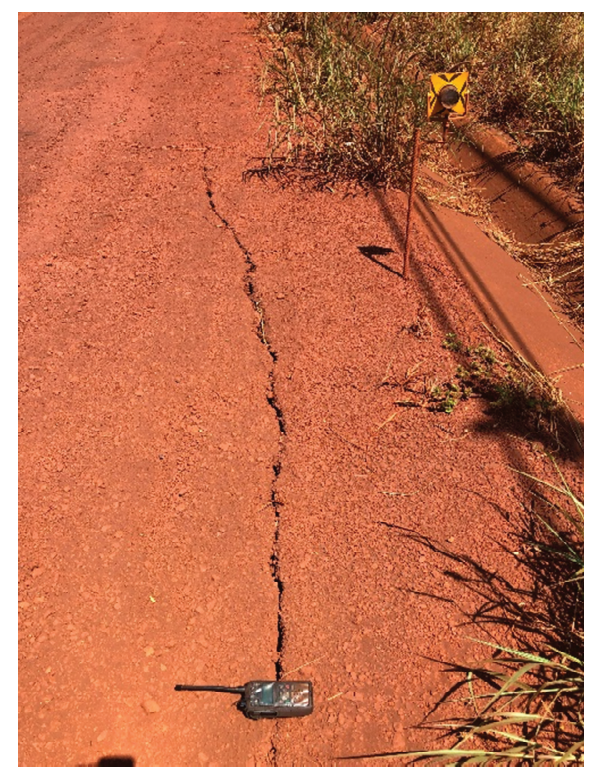

Figure 10 Cracking at the transfer house 7 area (CT-7), parallel to the soil embankment crest

After the evaluation of the three geotechnical monitoring data outcomes of the CT-7 area, satellite-based InSAR, survey monitoring and visual inspection, it was proven that it is useful to have multiple techniques to detect geotechnical movement. Each of them has its advantages and disadvantages, and they function as complementary methodologies.

Other than appreciating the monitoring methods and its particularities when analysing geotechnical monitoring data, it is imperative to understand the structure itself-the more information the geotechnical engineer has, the easier it is to tie movement to its causes. Some important information are, for example, the project as-built and as is, the materials' behaviour, the construction history, the current activities and equipment close to the structure (wells, pipes, hauling equipment, etc.), precipitation history, and water level.

\section{Conclusion}

At Serra Sul, ore and waste are transported from mining faces, to the processing plant and waste dumps respectively by conveyor belts. Most conveyors are located on top of cut-and-fill slopes and soil embankments, built to carry a road for conveyor infrastructure, which are currently the most significant concerns for the geotechnical team. This paper presented the current techniques applied at the Serra Sul Iron Ore Project to perform geotechnical monitoring, and illustrated an example of evaluation of data for a specific monitored area, CT-7.

The three current geotechnical monitoring methods used at the site are satellite-based interferometric radar (InSAR), survey monitoring with prisms and RTSs, and visual inspections. InSAR is a convenient tool for large-coverage surface deformation monitoring, such as Serra Sul. It can detect slow movement at the scale of millimetres over hundreds of square kilometres, where field instruments are not present and access for visual inspection is not available. However, the limitation of this technology is related to the decorrelation of the PSs, or temporal and geometrical decorrelation. It is unfeasible to have measurements over vegetated areas. PSs are usually located at civil infrastructure-such as roads, conveyor belts and bridges-and relatively steady ground such as overall open pit slopes, waste dumps, tailings and water dams, etc.

Prism monitoring has been used in the mining industry to detect movement at geotechnical structures. At Serra Sul, this technique is applied at locations of geotechnical interest, such as the cut-and-fill slopes near the conveyor belts and transfer houses. Currently, there are nine areas that are constantly monitored using RTSs. When movement is detected on either InSAR data or prism data, a detailed field investigation is necessary. Visual inspections are part of the routine of both operational and geotechnical staff. 
The CT-7 area was chosen to be presented in this study as it covers both an excavated slope and a soil embankment. The InSAR data available at this location is mostly along the conveyor belt itself, while prisms are distributed inside the perimeter of each project (CT-7 A, B, C, D and E), including the slope benches and the soil embankment edges.

The InSAR data relative to the evaluated time frame (15 August 2018 to 10 August 2019) has not shown significant movement. The four cumulative displacement maps indicated relative stability of the area. While, in September 2018 and April 2019, there was an indication of movement near the edges of the embankment through the survey monitoring instruments, at CT-7 C and D respectively. A detailed visual inspection was conducted by the geotechnical staff to investigate the causes of movement. Based on an overall understanding of the geotechnical structure, it was concluded that the first event might have happened due to equipment interference-a road grader could have pushed the instrument while levelling the ground surface. On the other hand, after the visual inspection of the second event, a tension crack was identified parallel to the embankment crest. It is believed that the anomaly developed due to the lack of compaction of the embankment near the edge (as, for safety reasons, compaction equipment might not approach the edges of embankments), together with the increase in pluviometry during the rainy season.

Within this study and the geotechnical monitoring practices applied at Serra Sul, it was possible to conclude that each method has its advantages and disadvantages. They might be used as complementary sources to evaluate movement, and if available, to provide redundant data. In order to have an effective geotechnical monitoring program, it is important to appreciate the particularities of each technology, and it's paramount to understand the structure itself to tie movement to its causes.

\section{Acknowledgement}

We are grateful to Vale S.A. for the concession of the data published in this paper and to all colleagues who contributed directly and indirectly to the development of this document.

\section{References}

Constantini, M, Chen, T, Xu, Y, Trillo, F, Vecchioli, F, Kong, L, Jiang, D \& Hu, Q 2011, 'High resolution ground deformations monitoring by COSMO-SkyMed PSP SAR Interferometry: Accuracy analysis and validation', Proceedings of FRINGE 2011, ESA Communications, Noordwijk.

Constantini, M, Malvarosa, F, Miniati, F \& de Assis, LM 2016, 'Operational monitoring of mines by COSMO-SkyMED PSP SAR interferometry', Proceedings of the Living Planet Symposium, European Space Agency, Paris, p. 392.

Ferretti, A, Prati, C \& Rocca, F 2001, 'Permanent scatters in SAR interferometry', IEEE Transactions on Geoscience and Remote Sensing, vol. 39, no. 1, pp. 8-20.

Vale S.A. 2013, Carajás S11D Iron Project. A new Impetus to Brazil's Sustainable Development, presentation, viewed 25 September 2019, http://www.vale.com/EN/initiatives/innovation/s11d/Documents/book-s11d-2013-en.pdf

Vale S.A. 2019, Annual Report Pursuant to Section 13 or 15(D) of the Securities Exchange Act of 1934 for the Fiscal Year Ended: December 31, 2018, United States Securities and Exchange Commission, Washington DC, viewed 3 March 2020, http://www.vale.com/EN/investors/information-market/annual-reports/20f/20FDocs/Vale_20-F\%20FY2018\%20\%20final_i.pdf 
An overview of the slope monitoring program at the Serra Sul Iron

MF Souza et al.

Ore Project, S11D, northern Brazil 